\title{
Investigation of patterning effect in ultrafast SOA-based optical switches
}

\author{
Xu, Jing; Zhang, Xinliang; Mørk, Jesper
}

Published in:

Proceedings of European Conference on Lasers and Electro-Optics Europe

Link to article, DOI:

10.1109/CLEOE-EQEC.2009.5196235

Publication date:

2009

Document Version

Publisher's PDF, also known as Version of record

Link back to DTU Orbit

Citation $(A P A)$ :

Xu, J., Zhang, X., \& Mørk, J. (2009). Investigation of patterning effect in ultrafast SOA-based optical switches. In Proceedings of European Conference on Lasers and Electro-Optics Europe (pp. Cl2.1). IEEE. https://doi.org/10.1109/CLEOE-EQEC.2009.5196235

\section{General rights}

Copyright and moral rights for the publications made accessible in the public portal are retained by the authors and/or other copyright owners and it is a condition of accessing publications that users recognise and abide by the legal requirements associated with these rights.

- Users may download and print one copy of any publication from the public portal for the purpose of private study or research.

- You may not further distribute the material or use it for any profit-making activity or commercial gain

- You may freely distribute the URL identifying the publication in the public portal 


\section{Investigation of patterning effect in ultrafast SOA-based optical switches

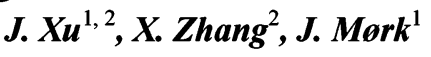

1. DTU Fotonik - Department of Photonics Engineering, Technical University of Denmark, Denmark

2. Wuhan National Laboratory for Optoelectronics (WNLO), Huazhong University of Science and Technology, China

SOA-based optical switches utilizing optical filtering techniques have been successfully demonstrated at ultrahigh bitrates up to $640 \mathrm{Gbit} / \mathrm{s}[1,2]$. However, large power penalties have been observed due to degraded OSNR as well as patterning effects $(\mathrm{PE})$ induced by slow carrier-lifetime limited decay processes. The PE, defined here as the ratio of the largest to the smallest switched peak pulse power [3], is usually estimated using pseudo-random binary sequence (PRBS) of length $2^{n}$-1, where bit pattern length $n$ should be chosen such that the full extent of memory effects in the device is captured. The use of long PRBS lengths is often prohibited in experiments by the temporal multiplexing techniques used to generate the signal and in simulations by the excessive computation time needed. Whether the use of $n=7[1,2]$ corresponding to a PRBS length of 255 bits is sufficient to capture the full impact of PE of the switches is thus still an open issue. Here we (i) derive a simple condition for the minimum bit pattern length, (ii) introduce an effective method for simulating patterning effects and prove its validity and (iii) use the method to analyse a specific configuration for high-speed signal processing.

As an example we analyze a configuration consisting of an SOA followed by an optical filter of bandwidth $\Delta f_{B W}$ and with a detuning $\Delta f$. Using the model of [3], Fig.la shows the PE versus $n$ for three bitrates $(B)$ and two effective recovery times, $\tau_{s}$ of the SOA, defined as the time needed for the carrier density to recover from $10 \%$ to $90 \%$ of the steady value. The PE is seen to increase with $n$ until it reaches a plateau of saturation at a critical bit-pattern length $\left(n_{c}\right)$. By analyzing the dynamics of the SOA and the properties of the PRBS we propose the following Equation

$$
n_{c}=\left\lceil B \times \tau_{s}\right\rceil+1
$$

where $\lceil X\rceil$ takes the smallest integer larger than $X$. The values from Eq. (1) are marked on Fig. 1a by star symbols and are seen to agree well with the full numerical simulations. It shows that a PRBS length of tens of megabits may be required in realistic situations (e.g., $B=160 \mathrm{Gbit} / \mathrm{s}, \tau_{s}=141 \mathrm{ps}$ ). A further analysis of PE curves under twelve combinations of three values of $B$ and four values of $\tau_{s}(32 \mathrm{ps}, 67 \mathrm{ps}$ added) indicates that PE captured by $n_{c}$ shows $\sim 90 \%$ of the maximum PE. Therefore, Eq. (1) can be viewed as a lower bound for bit pattern length that should be used in performance evaluations of the switches.
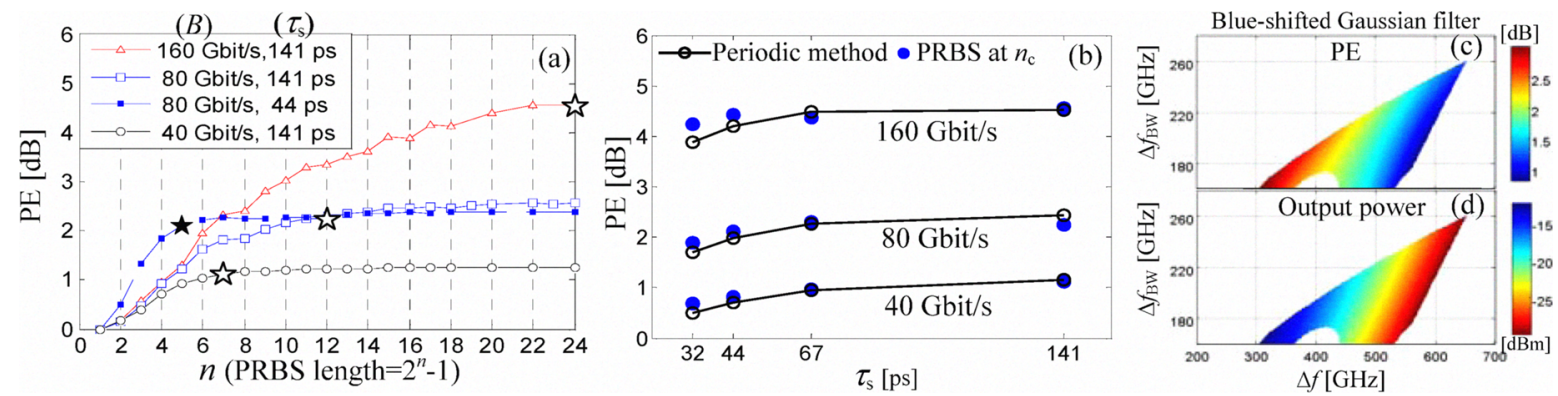

Fig. 1 (a) PE as a function of $n$. (b) Comparison between new method and PRBS. Dependence of (c) PE and (d) output power on the characteristics of the filter using new method.

Next, we propose a computationally very effective method to calculate the maximum PE. The method relies on the use of two pulse trains which would drive the SOA at two saturation extremes: one periodic with a repetition rate of $B$ and the other one consisting of a single pulse $(B=0)$. Therefore, the maximum and minimum switched peak power can be captured separately. Fig. $1 \mathrm{~b}$ compares the PE estimated by the new method and a full simulation with a PRBS sequence given by $n=n_{c}$. As seen, the periodic method gives a very good approximation to the full PRBS simulations at $n_{c}$, providing on the order of $\sim 90 \%$ of the maximum PE. The value is less than $100 \%$ because of overshoots encountered in the recovery process. Nevertheless, it shows that a lower limit, and actually a good approximation, to the maximum PE can be obtained very efficiently. Since this method is much less time-consuming than full PRBS simulations, it allows characterizations of the switches in a large parameter region. For example, the calculated dependence of $\mathrm{PE}$ on the characteristics of the filter is shown in Fig. 1c. The variation of the output power is shown by Fig. 1d. Only results of non-inverted pulses with ER $>10 \mathrm{~dB}$ and output power $>-30 \mathrm{dBm}$ are shown. As seen, the PE decreases as $\Delta f$ increases for a fixed $\Delta f_{B W}$. Simultaneously, however, the output power decreases, indicating a clear trade-off between PE and output power.

\section{References}

[1] Y. Liu, E. Tangdiongga, Z. Li, et al, "Error-free $320 \mathrm{~Gb} / \mathrm{s} \mathrm{SOA-based} \mathrm{wavelength} \mathrm{conversion} \mathrm{using} \mathrm{optical} \mathrm{filtering",} \mathrm{OFC'2005.} \mathrm{PDP28.}$ [2] E. Tangdiongga, Y. Liu, H. de Waardt, et al, "All-optical demultiplexing of 640 to $40 \mathrm{Gbits} / \mathrm{s}$ using filtered chirp of a semiconductor optical amplifier”, Opt. Lett. 32, 835(2007).

[3] Mads L. Nielsen, Jesper Mørk, Rei Suzuki, et al, "Experimental and theoretical investigation of the impact of ultra-fast carrier dynamics on highspeed SOA-based all-optical switches", Opt. Express 14, 331(2006) 